\title{
The Nucleus Reuniens of the Midline Thalamus Gates Prefrontal-Hippocampal Modulation of Ventral Tegmental Area Dopamine Neuron Activity
}

\author{
Eric C. Zimmerman and $\oplus^{\circledR}$ Anthony A. Grace \\ Departments of Neuroscience, Psychiatry, and Psychology, University of Pittsburgh, Pittsburgh, Pennsylvania 15260
}

The circuitry mediating top-down control of dopamine (DA) neurons in the ventral tegmental area (VTA) is exceedingly complex. Characterizing these networks will be critical to our understanding of fundamental behaviors, such as motivation and reward processing, as well as several disease states. Previous work suggests that the medial prefrontal cortex (mPFC) exerts a profound influence on VTA DA neuron firing. Recently, our group reported that inhibition of the infralimbic subdivision of the medial prefrontal cortex (ilPFC) increases the proportion of VTA DA neurons that are spontaneously active (i.e., "population activity") and that this effect depends on activity in the ventral subiculum of the hippocampus (vSub). However, there is no direct projection from the mPFC to the vSub. Anatomical evidence suggests that communication between the two structures is mediated by the nucleus reuniens of the midline thalamus (RE). Here, we used in vivo electrophysiological and behavioral approaches in rats to explore the role of the RE in the circuitry governing VTA DA neuron firing. We show that pharmacological stimulation of the RE enhances VTA DA neuron population activity and amphetamine-induced hyperlocomotion, a behavioral indicator of an over-responsive DA system. Furthermore, the effect of RE stimulation on population activity is prevented if vSub is also inhibited. Finally, pharmacological inhibition of ilPFC enhances VTA DA neuron population activity, but this effect does not occur if RE is also inhibited. These findings suggest that disruption of ilPFC-RE-vSub communication could lead to a dysregulated, hyperdopaminergic state, and may play a role in psychiatric disorders.

Key words: dopamine; thalamus; VTA

Significance Statement

Dopamine (DA) neurons in the ventral tegmental area (VTA) are involved in a variety of fundamental brain functions. To understand the neurobiological basis for these functions it is essential to identify regions controlling DA neuron activity. The medial prefrontal cortex (mPFC) is emerging as a key regulator of DA neuron activity, but the circuitry by which it exerts its influence remains poorly described. Here, we show that the nucleus reuniens of the midline thalamus gates mPFC control of VTA DA neuron firing by the hippocampus. These data identify a unique role for this corticothalamic-hippocampal circuit, and suggest that dysfunction in these regions likely influences the pathophysiology of psychiatric disorders.

\section{Introduction}

The afferent circuitry regulating the activity of dopamine (DA) neurons of the ventral midbrain, including the ventral tegmental area (VTA), is exceedingly complex (Sesack and Grace, 2010; Watabe-

\footnotetext{
Received April 27, 2016; revised July 1, 2016; accepted July 6, 2016.

Author contributions: E.C.Z. and A.A.G. designed research; E.C.Z. performed research; E.C.Z. analyzed data; E.C.Z. and A.A.G. wrote the paper.

This work was supported by National Institutes of Health Grants F30MH109199 (E.C.Z.), and MH57440 (A.A.G.). We thank all members of the Grace laboratory for their helpful advice and technical assistance.

E.C.Z. declares no competing financial interests. A.A.G. reports potential competing financial interests related to associations with the following companies: Johnson \& Johnson, Lundbeck, Pfizer, GlaxoSmithKline, Merck, Takeda, Dainippon Sumitomo, Otsuka, Lilly, Roche, Asubio, Abbott, Autofony, Janssen, and Alkermes.

Correspondence should be addressed to Eric C. Zimmerman, Department of Neuroscience, A210 Langley Hall, Pittsburgh, PA 15260.E-mail: ecz5@pitt.edu.

DOI:10.1523/JNEUROSCI.1402-16.2016

Copyright $\odot 2016$ the authors $\quad 0270-6474 / 16 / 368977-08 \$ 15.00 / 0$
}

Uchida et al., 2012; Beier et al., 2015; Lerner et al., 2015). Although a number of regions project directly to the VTA, numerous studies have shown that there are complex multisynaptic networks that potently impact DA neuron activity states (Floresco et al., 2003; Butts et al., 2011; Patton et al., 2013; Chang and Grace, 2014; Ferenczi et al., 2016). These circuits provide multiple sites of dynamic regulation and amplification of DA neuron output. Characterizing the mechanisms by which these afferent or "upstream" networks control DA neuron firing, and therefore DA tone in VTA output regions, will be fundamental to our understanding of complex behaviors, such as motivation and reward processing, as well as several disease states.

We have previously characterized a circuit comprising the ventral subiculum (vSub), the nucleus accumbens (NAc), and the ventral pallidum (VP), which potently influences DA system responsivity (Floresco et al., 2001, 2003; Lodge and Grace, 2007; 
Valenti et al., 2011). Stimulation of the vSub, via the NAc and VP, leads to disinhibition of VTA DA neurons and an increase in the proportion of VTA DA neurons that are spontaneously active (i.e., "population activity"). This effect is accompanied by DA release in the NAc (Floresco et al., 2003) and an increase in amphetamine-induced hyperlocomotion (White et al., 2006), a behavioral correlate of DA system responsivity (Moore et al., 2001; Lodge and Grace, 2007; Gill et al., 2011; Valenti et al., 2011; Chang and Grace, 2013). Population activity is a key parameter of DA neuron firing, because DA neurons can only exhibit rapid, phasic, stimulus-driven burst firing (Grace and Bunney, 1984) if they are spontaneously active (Lodge and Grace, 2006). Therefore, the vSub-NAc-VP circuit acts as a critical gain modulator of behaviorally salient DA neuron outputs. In addition, this circuit controlling population activity has been shown to play essential roles in animal models of schizophrenia, depression, and drug abuse (Lodge and Grace, 2007; Chang and Grace, 2014; Belujon et al., 2016).

Hippocampal control of VTA DA neuron population activity is in turn potently modulated by the medial prefrontal cortex (mPFC). Specifically, attenuation of activity in the infralimbic subdivision of the medial prefrontal cortex (ilPFC; but not the prelimbic subdivision) increases population activity, and this effect is dependent on the vSub (Patton et al., 2013). However, no direct projection exists between the ilPFC and the vSub (Laroche et al., 2000; Vertes, 2004). The nucleus reuniens of the midline thalamus (RE) forms an anatomical link between the mPFC and the hippocampus, sending a potent, glutamatergic projection to the hippocampus (Herkenham, 1978; Vertes et al., 2006) that densely innervates the stratum lacunosum-moleculare of the dorsal and ventral CA1, as well as the molecular layer of the dorsal and ventral subiculum (Bokor et al., 2002; Vertes et al., 2006; Hoover and Vertes, 2012). Electrophysiological studies show that the RE excites CAl neurons (Dolleman-Van der Weel et al., 1997). Fibers from the RE also distribute throughout layers 1 and $5 / 6$ of the mPFC, including dense projections to the ilPFC (Vertes et al., 2006). In turn, the RE receives reciprocal connections from the vSub and the ilPFC, forming a functional network (McKenna and Vertes, 2004; Varela et al., 2014).

Given these rich interconnections between the ilPFC, RE, and vSub, the RE could play a role in the afferent control of VTA DA neuron activity. However, this possibility has not been evaluated experimentally. In the current study, we use in vivo, circuit-based electrophysiological and behavioral approaches in rats to explore the role of RE in the descending cortical-subcortical circuitry governing VTA DA neuron firing.

\section{Materials and Methods}

Animals. All experiments were performed in accordance with the guidelines outlined in the United States Public Health Service Guide for Care and Use of Laboratory Animals and were approved by the Institutional Animal Care and Use Committee of the University of Pittsburgh. All experiments were performed in adult ( $>65 \mathrm{~d}$ old) male Sprague Dawley rats (105 rats total; $300-450 \mathrm{~g}$ ).

Electrophysiology. Animals were anesthetized with an initial dose of chloral hydrate (Sigma-Aldrich; $400 \mathrm{mg} / \mathrm{kg}$, i.p.) and were supplemented periodically (intraperitoneally) to maintain suppression of the hindlimb withdrawal reflex. Rats were then placed in a stereotaxic frame (Kopf) and body temperature was maintained at $37^{\circ} \mathrm{C}$ with a temperaturecontrolled heating pad and rectal probe (Fintronics). In vivo, extracellular recordings were performed using single glass microelectrodes (WPI; impedance 6-8 M $\Omega$ ) filled with a $2 \%$ Chicago sky blue (Sigma-Aldrich) solution in $2 \mathrm{M} \mathrm{NaCl}$. This impedance ensures that we were able to clearly resolve the waveform from a single cell with a very high signal-to-noise ratio and without contamination from neighboring cells. Following a craniotomy, electrodes were lowered into the VTA in nine sequential, vertical "tracks" at $0.2 \mathrm{~mm}$ intervals in a predetermined grid pattern in the $x-y$ plane via hydraulic micropositioner (Kopf). Tracks began at the following coordinates from bregma/skull surface (in $\mathrm{mm}$ ): anteroposterior (AP), -5.3 ; mediolateral (ML), 0.6; dorsoventral (DV), -6.5 to -9 , according to the Paxinos and Watson brain atlas (Paxinos and Watson, 2013), and sampled a block of tissue from AP -5.3 to -5.7 and ML $0.6-1.0$, as previously described (Chang and Grace, 2014). Individual, putative DA neurons were recorded with open filter settings (low pass, 10 $\mathrm{Hz}$; high pass, $16 \mathrm{kHz}$ ) enabling identification using well established criteria, including (1) slow $(2-10 \mathrm{~Hz})$, irregular, or bursting firing pattern; (2) long-duration ( $>2.2 \mathrm{~ms}$ ) biphasic action potential with initial segment-somatodendritic positive phase break; and (3) temporary inhibition of firing during tail or foot pinch (Grace and Bunney, 1983; Ungless and Grace, 2012). Three properties of identified DA neurons were measured: (1) population activity, quantified as the average number of spontaneously active DA neurons per electrode track, i.e., "cells/track" (calculated for each rat); (2) average firing rate, and (3) percentage of spikes occurring in bursts. Burst initiation was defined as the occurrence of two spikes with an interspike interval of $80 \mathrm{~ms}$, and burst termination as the occurrence of an interspike interval of $160 \mathrm{~ms}$, as previously described (Grace and Bunney, 1984). Each neuron was recorded for $\geq 3$ min and, given the typical $\sim 4 \mathrm{~Hz}$ firing rate of identified DA neurons (Grace and Bunney, 1983; Ungless and Grace, 2012), this resulted in $\sim 720$ spikes being included in the analysis of firing properties for each neuron.

Intracranial infusions in anesthetized rats. Local infusions were performed in anesthetized animals immediately before VTA DA neuron recordings. Using the stereotaxic frame, a guide cannula (23 gauge) was placed above the ilPFC, RE, and/or vSub at the following coordinates from bregma/skull surface (in mm): ilPFC: AP, +2.7; ML, 0.5; DV, - 3.5; RE: AP, -2.2 ; ML, 2.3 ; DV,$-7.2 ; 15^{\circ}$ angle from vertical; vSub: AP, -5.5; ML, 4.8; DV, -7.1 , according to the Paxinos and Watson brain atlas (Paxinos and Watson, 2013). Subsequently, an infusion cannula (33 gauge) was inserted into the guide cannula, extending $1 \mathrm{~mm}$ beyond the tip of the guide cannula. Pharmacological agents dissolved in Dulbecco's PBS (dPBS; Sigma-Aldrich) or dPBS vehicle only were administered through the infusion cannula at a rate of $0.5 \mu \mathrm{l} / \mathrm{min}$. The guide cannula was left in place for $3 \mathrm{~min}$ following infusions to allow for adequate diffusion of drug. Drug doses were as follows for all experiments: ilPFC: TTX, $1 \mathrm{M}$ in $0.5 \mu \mathrm{l}$; RE: NMDA, $0.75 \mu \mathrm{g}$ in $0.2 \mu$ l; TTX, $1 \mathrm{M}$ in $0.2 \mu \mathrm{l}$; vSub: TTX, $1 \mathrm{M}$ in $0.5 \mu \mathrm{l}$.

Chemical stimulation was deliberately used to enable stable, longduration neuronal excitation without the confounds associated with current spread, activation of fibers of passage, or potential lesions during extended electrical or optical stimulation. All pharmacological agents were injected at doses reported previously to induce specific behavioral and/or neurochemical effects (Lodge and Grace, 2007; Valenti et al., 2011; Patton et al., 2013). Rats received only one injection per region and DA cell recordings were typically performed from $10 \mathrm{~min}$ to $2.5 \mathrm{~h}$ after infusions.

Survival surgery and cannula implantation for behavioral studies. All survival surgeries were performed under general anesthesia in a sterile environment. Briefly, rats were anesthetized with isoflurane (induction: $5 \%$; maintenance: $1-3 \%$ in oxygen) and placed in a stereotaxic apparatus using blunt, atraumatic ear bars. Bilateral cannulae (23 gauge) were implanted in the RE [coordinates from bregma/skull surface (in mm): AP, $-2.2 ; \mathrm{ML}, 2.3 ; \mathrm{DV},-7.2 ; 15^{\circ}$ angle from vertical $]$ and fixed in place with dental cement and anchor screws. Once the cement was dry, antibiotic cream was applied to the wound edge (Neosporin), and the rat was removed from the stereotaxic frame and monitored closely until conscious. Rats received postoperative analgesia (carpofen $5 \mathrm{mg} / \mathrm{kg}$, i.p., once per day for $72 \mathrm{~h}$ and Tylenol syrup in softened rat chow $5 \% \mathrm{v} / \mathrm{w}$ available ad libitum for $72 \mathrm{~h}$ ) and were allowed to recover for $\geq 1$ week before behavioral experiments.

Amphetamine-induced hyperlocomotion. Following surgeries, rats were housed in a reverse light/dark cycle room (lights on 7:00 P.M. to 7:00 A.M.) for $\geq 1$ week before behavioral experiments. Baseline locomotor 

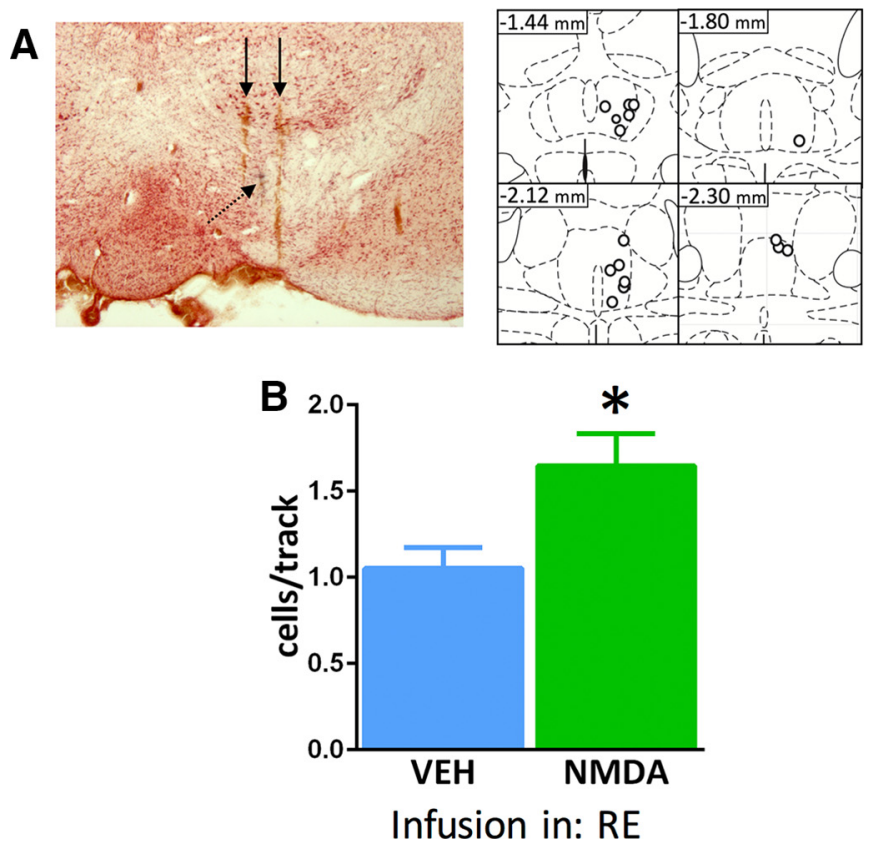

C
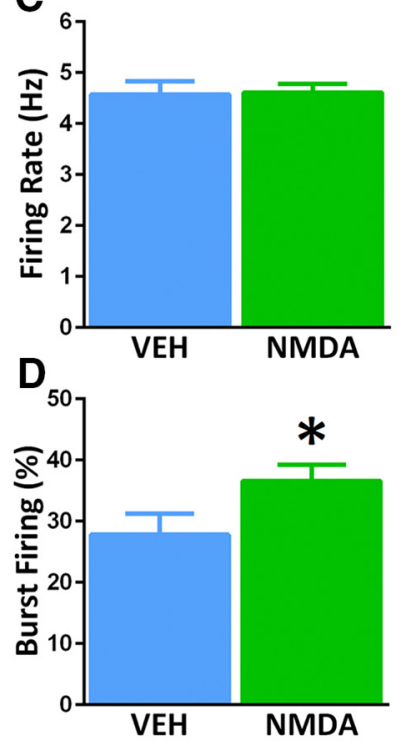

E

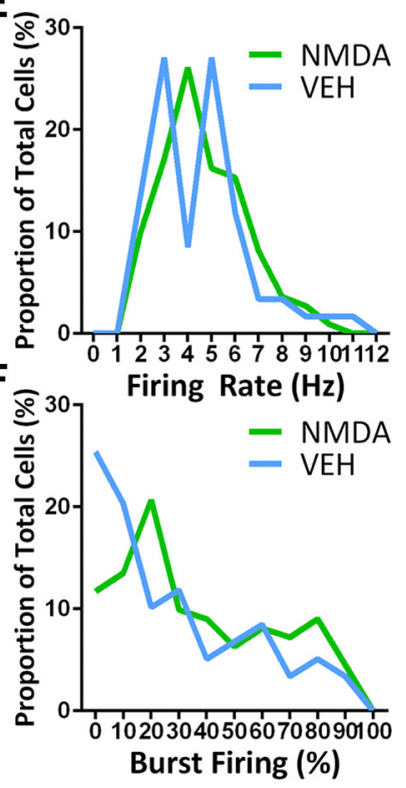

Figure 1. Activation of the RE produced an enhancement of VTA DA neuron population activity. A, Left, Representative image of electrode tracks (solid black arrows) and electrode tip (dashed arrow) in the VTA. Right, Representation of histological placements of infusion cannulae into the RE (open circles). $\boldsymbol{B}$, Activating the RE with NMDA enhanced the number of spontaneously active DA neurons firing in the VTA (expressed as cells/track, green bar) compared with infusion of vehicle (VEH; blue bar). C, D, The average firing rate of spontaneously active DA cells was not affected by infusion of NMDA into the RE, but the percentage of cells firing in bursts was increased. $E$, $F$, Distribution of firing rate and burst firing were not affected by infusion of NMDA into the RE (Kolmogorov-Smirnov test). ${ }^{*} p<0.05$ (unpaired $t$ test). VEH, $n=8$ rats; NMDA, $n=8$ rats; VEH, $n=59$ neurons; NMDA, $n=111$ neurons. Data are represented as mean \pm SEM.

activity and amphetamine-induced hyperlocomotion were measured by beam breaks in the $x-y$ plane of an open-field arena (Coulborn) and analyzed in 5 min epochs. Following measurement of baseline locomotor activity, NMDA $(0.75 \mu \mathrm{g}$ in $0.2 \mu \mathrm{l})$ or dPBS vehicle was injected into the $\mathrm{RE}$ via the previously implanted guide cannula, followed immediately by D-amphetamine sulfate $(0.75 \mathrm{mg} / \mathrm{kg}$, i.p. $)$. Amphetamine-induced hyperlocomotion was then measured for $60 \mathrm{~min}$.

Histology. After electrophysiology, the recording site was marked via electrophoretic ejection of Chicago sky blue dye from the tip of the recording electrode ( $-25 \mu \mathrm{A}$ constant current, 20-30 min). All rats were killed and decapitated. Their brains were removed, fixed for $\geq 48 \mathrm{~h} \mathrm{(8 \%}$ $\mathrm{w} / \mathrm{v}$ paraformaldehyde in PBS), and cryoprotected ( $25 \% \mathrm{w} / \mathrm{v}$ sucrose in PBS) until saturated. Brains were sectioned ( $60 \mu \mathrm{m}$ coronal sections), mounted onto gelatin-chrom alum-coated slides, and stained with cresyl violet for histochemical verification of electrode and/or acute/chronically implanted cannula placement. All histology was performed with reference to a stereotaxic atlas (Paxinos and Watson, 2013). Only data from animals with accurate placements in all regions were included in the analysis.

Analysis. Electrophysiological analysis of DA neuron activity was performed using commercially available software (LabChart and NeuroExplorer). Locomotor behavior was recorded using TruScan software. All data are represented as the mean \pm SEM, unless otherwise stated. All statistics were calculated using the GraphPad Prism software program (GraphPad Software).

\section{Results}

RE activation increases VTA DA neuron population activity

We showed previously that the vSub exerts a profound influence on VTA DA neuron activity (Floresco et al., 2003; Lodge and Grace, 2006, 2007; Patton et al., 2013). Given the dense, excitatory projections from the RE to the vSub (Dolleman-Van der Weel et al., 1997; Bertram and Zhang, 1999; Vertes et al., 2006), we tested whether RE activation would also affect VTA DA neuron activity. Following infusion of vehicle into the RE (dPBS; $n=$ 8 rats and 59 neurons; Fig. $1 A$ ), we found an average of $1.05 \pm 0.1$ spontaneously active DA neurons per electrode track in the VTA (i.e., "cells/track"), with an average firing rate of $4.57 \pm 0.3 \mathrm{~Hz}$ and $27.82 \pm 3.4 \%$ of action potentials fired in bursts (Fig. $1 B-F$ ), all of which are consistent with previous findings in untreated animals (Lodge and Grace, 2007; Chang and Grace, 2014; Gill et al., 2014). In contrast, following NMDA infusion into the RE ( $0.75 \mu \mathrm{g}$ in $0.2 \mu \mathrm{l} ; n=8$ rats and 111 neurons), we observed a nearly $63 \%$ increase in VTA DA neuron population activity over controls $\left(1.65 \pm 0.2\right.$ cells/track; unpaired $t$ test, $t_{(14)}=2.69, p=$ $0.02)$, with no significant change in firing rate $(4.61 \pm 0.2 \mathrm{~Hz})$. Infusion of NMDA into regions adjacent to the RE, including the interanteromedial, ventromedial, and paraxiphoid nuclei of the thalamus, had no effect on VTA DA neuron activity (data not shown). We also observed a small but significant increase in burst firing following NMDA infusion into the RE $(36.61 \pm 2.6 \%$, unpaired $t$ test, $\left.t_{(168)}=2.00, p=0.047\right)$. These data show that RE stimulation is sufficient to enhance VTA DA neuron population activity.

\section{RE activation increases amphetamine-induced hyperlocomotion}

Given that VTA DA neuron population activity correlates with amphetamine-induced hyperlocomotion (Moore et al., 2001; Lodge and Grace, 2007; Gill et al., 2011; Valenti et al., 2011; Chang and Grace, 2013), we measured the locomotor response to amphetamine following acute infusion of dPBS vehicle or NMDA into the RE (Fig. $2 A$ ) in a separate group of awake, behaving rats. Rats that received an acute NMDA infusion $(0.75 \mu \mathrm{g}$ in $0.2 \mu \mathrm{l} ; n=8$ rats) into the RE displayed a significantly enhanced locomotor response to D-amphetamine sulfate injection $(0.75 \mathrm{mg} / \mathrm{kg}$, i.p.) compared with vehicle controls ( $n=13$ rats), both when quantified as total distance traveled (Fig. $2 B$, unpaired $t$ test, $t_{(19)}=2.22, p=0.04$ ) and ambulatory distance in discrete time bins (Fig. $2 C$; two-way repeated-measures ANOVA, main effect of treatment $F_{(1,19)}=4.9, p=0.03$ and treatment $\times$ time 

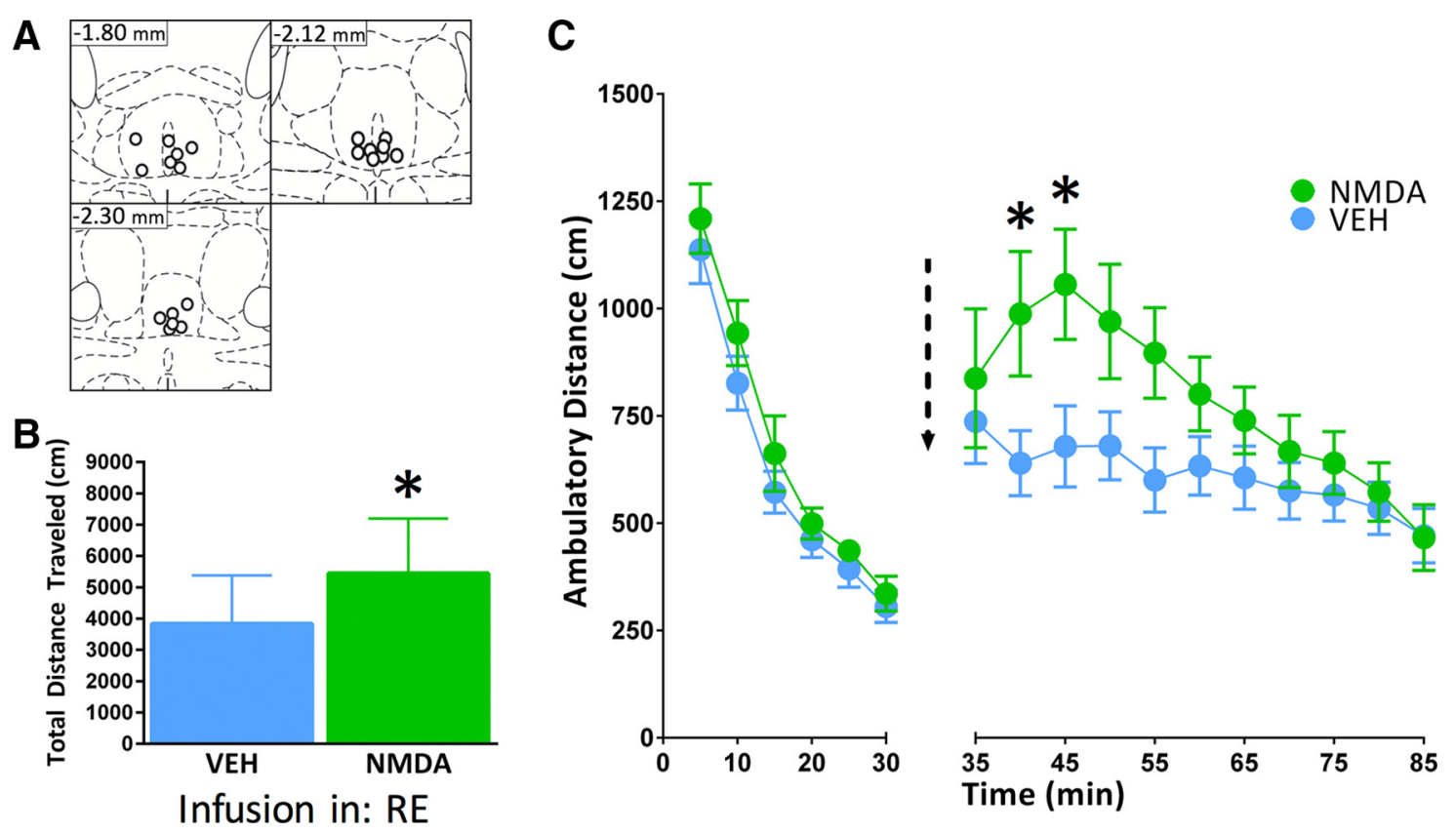

Figure 2. Activation of the RE increased amphetamine-induced hyperlocomotion. $\boldsymbol{A}$, Representation of histological placements of infusion cannulae into the RE (open circles). D-amphetamine sulfate $(0.75 \mathrm{mg} / \mathrm{kg}$, i.p.) was delivered immediately after acute microinjection of NMDA or dPBS vehicle (VEH) into the RE (both represented by dashed arrow). Baseline locomotor activity (0 -30 $\mathrm{min}$ ) and amphetamine-induced hyperlocomotion (35-90 min) were then measured. $\boldsymbol{B}$, Pharmacological activation of RE increased total distance traveled in the 60 min postinjection period compared with controls (unpaired $t$ test, ${ }^{*} p<0.05$ ). C, Pharmacological activation of the RE increased ambulatory distance during the postinjection period (two-way repeated-measures ANOVA, Holm-Sidak post hoc, $\left.{ }^{*} p<0.05\right)$. VEH, $n=13$ rats; NMDA $n=8$ rats. Data are represented as mean \pm SEM.

interaction $F_{(8,152)}=2.35, p=0.04$, Holm-Sidak post hoc). Therefore, both VTA DA neuron population activity and the locomotor response to amphetamine are increased by $\mathrm{RE}$ activation.

\section{The effect of RE activation on VTA DA neuron population activity requires the vSub}

Given evidence that the vSub potently controls VTA DA neuron activity (Floresco et al., 2003; Lodge and Grace, 2006, 2007; Patton et al., 2013), we examined whether the enhancement of VTA DA neuron population activity following RE activation was dependent on the vSub. This was tested by pharmacologically inactivating the vSub by TTX infusion ( $1 \mu \mathrm{M}$ in $0.5 \mu \mathrm{l}$ of dPBS) during simultaneous activation of the RE by NMDA infusion $(0.75 \mu \mathrm{g}$ in $0.2 \mu \mathrm{l}$; Fig. $3 A)$. Rats receiving either vehicle infusion in both regions, or vehicle in the RE and TTX in the vSub, exhibited similar DA neuron firing properties (dPBS/dPBS: $0.98 \pm 0.08$ cells/track, $4.40 \pm 0.3 \mathrm{~Hz}$, $36.30 \pm 4.1 \%, n=8$ rats and 40 neurons; dPBS/TTX: $0.90 \pm 0.2$ cells/track, $4.46 \pm 0.3 \mathrm{~Hz}, 31.65 \pm 4.1 \%, n=8$ rats and 54 neurons; Fig. $3 B-F)$. These findings are consistent with previous data from our group in untreated animals (Lodge and Grace, 2007; Patton et al., 2013). In addition, vehicle infusion into the vSub did not attenuate the enhancement of VTA DA neuron population activity observed following NMDA infusion into the RE $(1.56 \pm 0.2$ cells/track, $4.33 \pm 0.2 \mathrm{~Hz}, 31.43 \pm 2.9 \%, n=10$ rats and 107 neurons), which was significantly greater than in control animals (one-way ANOVA, main effect of treatment $F_{(3,28)}=5.7, p=0.004$, Tukey's post hoc) and consistent with our findings above (Fig. 1). In contrast, infusion of TTX into the vSub completely abolished the effect of RE activation on VTA DA neuron population activity: animals in this group $(n=$ 6 rats and 41 neurons) displayed $0.98 \pm 0.08$ active cells/track on average, which was not different from controls (one-way ANOVA, $95 \%$ CI of the difference: -0.65 to 0.49 ). In addition, no changes in firing rate $\left(4.55 \pm 0.2 \mathrm{~Hz}\right.$; one-way ANOVA, $F_{(3,238)}=0.12, p=$
$0.95)$ or burst firing $\left(31.32 \pm 3.6 \%\right.$, one-way ANOVA, $F_{(3,237)}=$ $0.33, p=0.80$ ) were observed in this group compared with control animals. These findings confirm that the vSub is necessary for RE stimulation to increase VTA DA neuron population activity.

\section{ilPFC control of VTA DA neuron population activity requires the RE}

We have shown previously that excitation or inhibition of the ilPFC bidirectionally modulates VTA DA neuron population activity. ilPFC inactivation induces an increase in population activity that does not occur following simultaneous vSub inhibition (Patton et al., 2013). Given that there is no direct projection from the ilPFC to the vSub (Laroche et al., 2000; Vertes, 2004), we tested whether the RE could be mediating the effect of ilPFC inhibition on VTA DA neuron population activity. This was tested by pharmacologically inactivating the RE by TTX infusion ( $1 \mu \mathrm{M}$ in $0.2 \mu \mathrm{l}$ of dPBS) during simultaneous inactivation of the ilPFC by TTX infusion $(1 \mu \mathrm{M}$ in $0.5 \mu \mathrm{l}$ of dPBS; Fig. $4 A$ ). In rats receiving either vehicle in both regions, or vehicle in the ilPFC and TTX in the RE, the number of spontaneously firing DA neurons per electrode track, firing rate, and burst firing were comparable (dPBS/dPBS: $1.0 \pm 0.1$ cells/track, $4.21 \pm 0.2$ $\mathrm{Hz}, 28.5 \pm 3.3 \%, n=10$ rats and 65 neurons; dPBS/TTX: $1.0 \pm 0.2$, $4.2 \pm 0.2 \mathrm{~Hz}, 30.4 \pm 3.4 \%, n=11$ rats and 68 neurons; Fig. $4 B-F$ ). These findings are consistent with previous data from our group in untreated animals (Patton et al., 2013). In addition, vehicle infusion in the RE did not influence the increase in VTA DA neuron population activity observed following TTX infusion into the ilPFC (1.60 \pm 0.2 cells/track, $4.67 \pm 0.2 \mathrm{~Hz}, 27.15 \pm 2.8 \%, n=7$ rats and 83 neurons), in which we observed a significant increase over controls (one-way ANOVA, main effect of treatment $F_{(3,32)}=6.7, p=0.001$, Tukey's post hoc). However, infusion of TTX into the RE completely prevented the effect of ilPFC inhibition on VTA DA neuron population activity ( $n=8$ rats and 40 neurons; $0.58 \pm 0.08$ cells/track), making this group statistically indistinguishable from controls (one- 

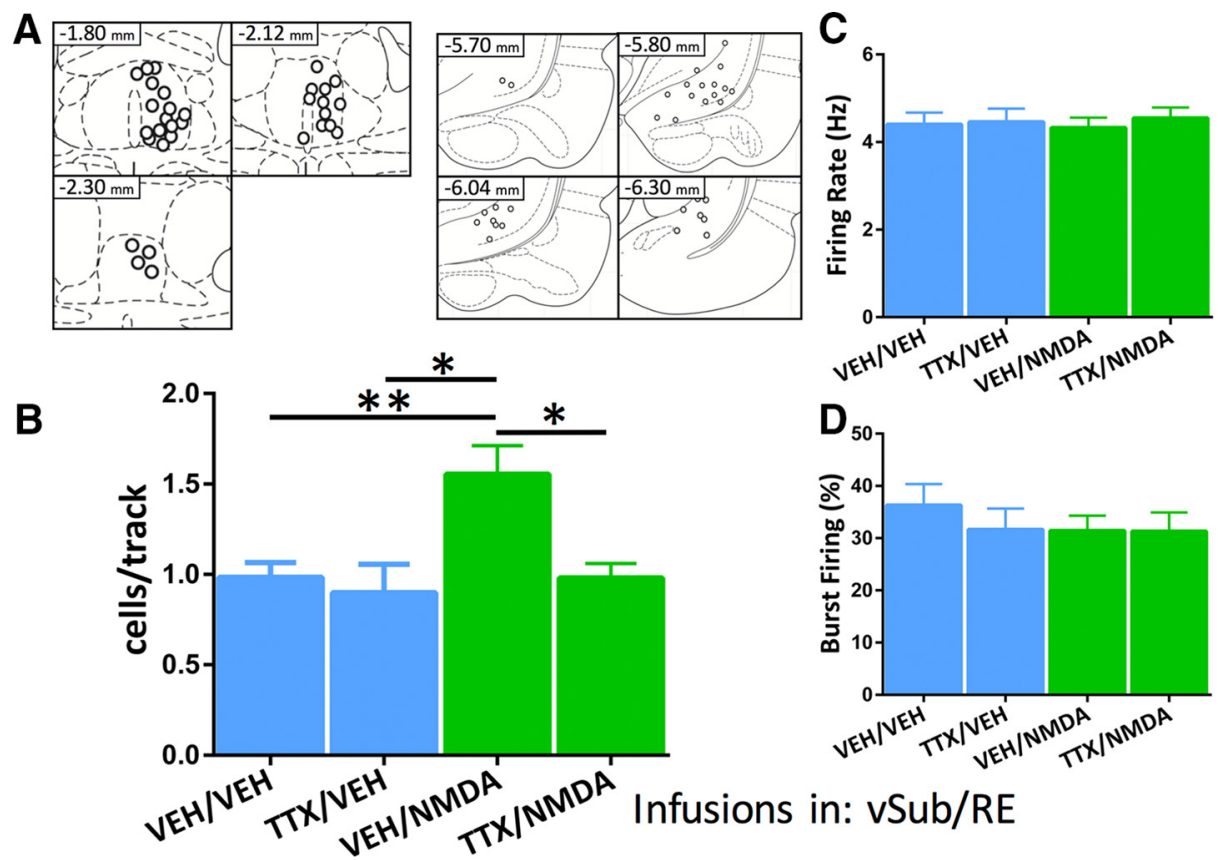
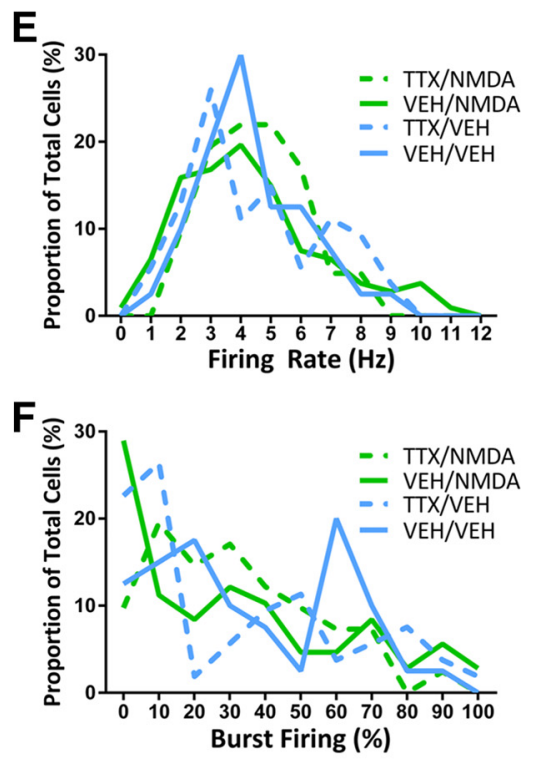

Figure 3. EnhancedVTADA neuron population activity following REactivation was prevented by inhibition of the vSub. $A$, Representation of histological placements of infusion cannulae into the RE (left) and thevSub (right; open circles). TTX or dPBS vehicle (VEH) was injected into the SSub, followed immediately by injection of NMDA or dPBS vehicle into the RE. VTA DA neuron population activity, firing rate, and burst firing were then measured. $\boldsymbol{B}$, Pharmacological activation of the RE increased population activity, while parallel inhibition of the vSub prevented this effect. $C, D$, The firing rate of spontaneously active $D A$ cells and the percentage of cells firing in bursts were not affected by any manipulation. $E$, $F$, Distribution of firing rate and burst firing were not affected by infusion of NMDA into the RE (Kruskal-Wallis test, firing rate, $H=$ $1.70, p=0.64$; bursting, $H=2.15, p=0.54$ ). ${ }^{*} p<0.05,{ }^{* *} p<0.01$ (one-way ANOVA, Tukey's posthoc). $x$-axis in $B-D$ is infusions in vSub/RE. $n=6-10$ rats/group; $n=40-107$ neurons/group. Data are represented as mean \pm SEM.
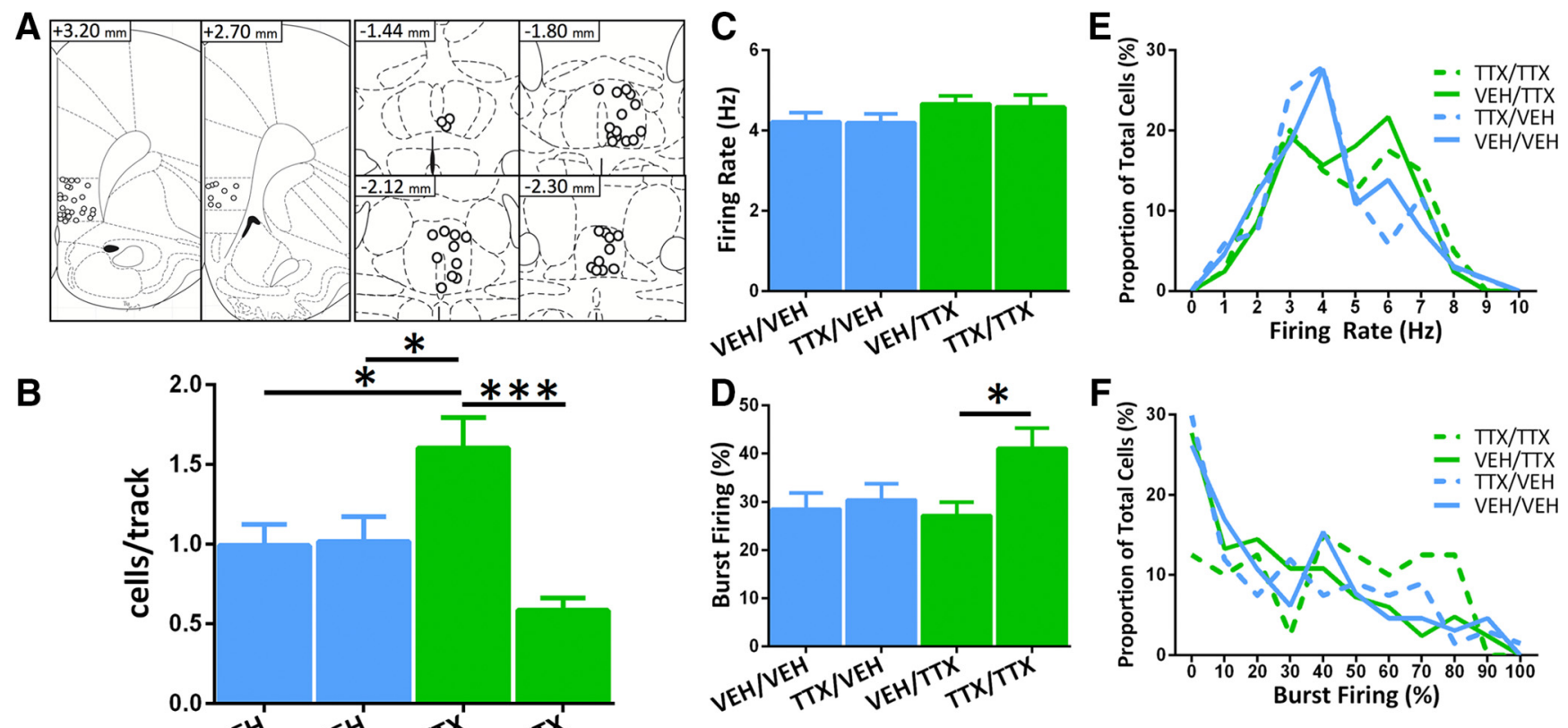

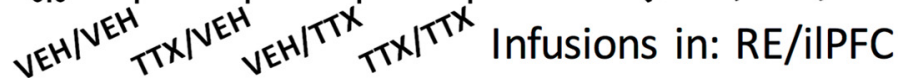

Figure 4. Enhanced VTA DA neuron population activity following iPFC inactivation was prevented by inhibition of the RE. A, Representation of histological placements of infusion cannulae into the ilPFC and the RE (open circles). TTX or dPBS vehicle (VEH) was injected into the RE, followed immediately by injection of TTX or dPBS vehicle into the ilPFC. VTADA neuron population activity, firing rate, and burstfiring were then measured. $\boldsymbol{B}$, Pharmacological inhibition of ilPFC increased population activity, while parallel inhibition of the RE prevented this effect. $\boldsymbol{C}, \boldsymbol{D}$, The firing rate of spontaneously active DA cells was not affected by any manipulation, while the percentage of cells firing in bursts was significantly enhanced in the TTX/TTX group. $E, F$, Distribution of firing rate and burst firing were not affected by infusion of NMDA into the RE(Kruskal-Wallistest, firing rate, $H=0.060, p=0.99$; bursting, $H=0.54, p=0.91$ ). ${ }^{*} p<0.05,{ }^{* * *} p<0.001$ (one-way ANOVA, Tukey's posthoc). $x$-axis in $B-D$ is infusions in RE/iPFC. $n=7-11$ rats/group; $n=40-83$ neurons/group. Data are represented as mean \pm SEM. 
way ANOVA, $95 \%$ CI of the difference: -0.16 to 0.97$)$. In addition, combined infusion of TTX into the ilPFC and the RE resulted in a small but statistically significant enhancement of burst firing (oneway ANOVA, main effect of treatment $F_{(3,251)}=2.7, p=0.046$, Tukey's post hoc). These findings confirm that activity in the RE is necessary for the effect of ilPFC inhibition on increasing VTA DA neuron population activity, and suggest that the RE acts as a necessary intermediary between the ilPFC and the vSub, playing a crucial role in cortical modulation of VTA DA neuron activity.

\section{Discussion}

We present evidence demonstrating that the RE is a novel region involved in control of VTA DA neuron population activity. Pharmacological stimulation of the RE enhances DA neuron population activity, without affecting average firing rate, and mildly enhancing burst firing. The same stimulation paradigm also enhances amphetamine-induced hyperlocomotion, which strongly correlates with DA system responsivity (Moore et al., 2001; Lodge and Grace, 2007; Gill et al., 2011; Valenti et al., 2011; Chang and Grace, 2013). Furthermore, we show that the effect of RE stimulation is prevented if the vSub is also inhibited, suggesting that activity in the vSub is necessary for the RE to drive VTA DA neuron firing. Finally, inactivation of the RE prevents the increase in VTA DA neuron population activity observed following ilPFC inhibition, suggesting that the ilPFC potently regulates RE drive of VTA DA neuron activity.

We and other groups have shown previously that stimulation of the vSub increases VTA DA neuron population activity and amphetamine-induced hyperlocomotion, without affecting firing rate or burst firing (Floresco et al., 2001, 2003; Hammad and Wagner, 2006; White et al., 2006). In addition, the RE has been shown to drive activity in CA1 and subiculum via asymmetric synapses onto the distal dendrites of pyramidal neurons (Wouterlood et al., 1990; Dolleman-Van der Weel et al., 1997; Bertram and Zhang, 1999). Therefore, the current findings suggest that stimulation of the RE enhances population activity and amphetamine-induced hyperlocomotion via direct, as well as indirect (via CA1), excitation of the vSub. Multiple previous studies have characterized the role of the $\mathrm{RE}$ in mediating communication between the $\mathrm{MPFC}$ and the hippocampus in behaviors requiring intact spatial and working memory (Hembrook and Mair, 2011; Hembrook et al., 2012; Cassel et al., 2013; Cholvin et al., 2013; Prasad et al., 2013; Duan et al., 2015; Ito et al., 2015; Layfield et al., 2015; Prasad et al., 2016; i.e., predominantly dorsal hippocampal functions). However, the present work is one of the first to show that the RE modulates ventral hippocampal functions, which is consistent with the fact that projections from the RE to the ventral hippocampus are the most dense of any RE efferents to the hippocampus (Herkenham, 1978; Hoover and Vertes, 2007; Varela et al., 2014).

We have shown previously that the ilPFC bidirectionally modulates VTA DA neuron population activity: inhibition of ilPFC enhances VTA DA neuron population activity, and this effect is dependent on the vSub, whereas excitation of the ilPFC attenuates VTA DA neuron population activity, and this effect depends on the basolateral amygdala (Patton et al., 2013). However, there are multiple potential pathways between the ilPFC and the vSub that could mediate the effect of ilPFC inhibition. The current findings provide strong evidence that the RE constitutes the connection by which the ilPFC can control vSub drive of VTA DA neuron activity. This finding is consistent with those of several studies characterizing monosynaptic interconnections between the ilPFC and the RE (Vertes, 2002; McKenna and Vertes, 2004; Hoover and Vertes, 2007). ilPFC projections to the RE are likely glutamatergic, making it apparently paradoxical that inhibition of the ilPFC could lead to drive of the
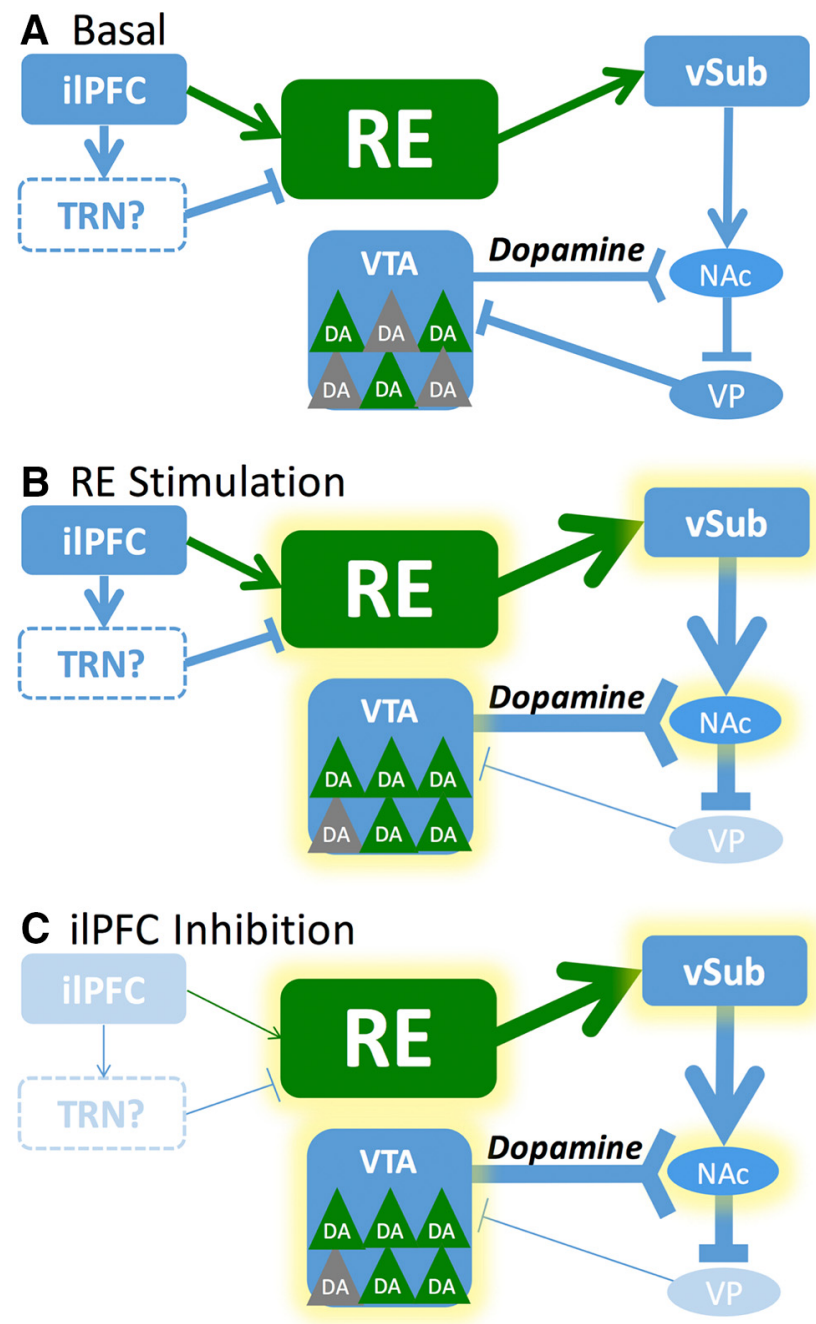

Figure 5. Schematic representation of the proposed pathways by which the RE could act to modulate VTA DA neuron activity. $\boldsymbol{A}$, In the baseline state, this circuitry is in balance, resulting in a typical proportion of spontaneously active (green triangles) and quiescent (gray triangles) DA neurons in the VTA (i.e., population activity). $\boldsymbol{B}$, When the RE is stimulated with NMDA, this results in an increase in vSub activity, and a subsequent enhancement of population activity (indicated by higher number of green triangles) via previously described subcortical circuitry. $\boldsymbol{C}$, When the ilPFC is inhibited, this results in an increase in population activity in an analogous fashion to what occurs following RE stimulation. The manner in which IPFC inhibition could result in enhanced activity of the RE has not been described, although one possibility would be via the inhibitory reticular nucleus of the thalamus (TRN).

vSub via the RE. However, there is mounting evidence that cortical regions may influence excitability of thalamic circuits via feedforward inhibition mediated by the reticular nucleus of the thalamus (Cornwall et al., 1990; Paz et al., 2011; Pratt and Morris, 2015; Wimmer et al., 2015). In this context, our findings would suggest that the ilPFC provides a potent down-modulation of RE drive of the hippocampus via the reticular thalamus. The finding that inhibition of the RE alone did not alter VTA DA neuron population activity does not preclude this model, because the RE likely exhibits low levels of activity at baseline in the anesthetized state. This model could explain the effects of ilPFC hyperactivity, which is proposed to play a role in models of depression (Belujon and Grace, 2014; Chang and Grace, 2014), in disrupting limbic emotional influences on memory processes. It also implies that dysfunction in the ilPFC would remove any feedforward inhibition provided by the reticular thalamus, leading to RE-vSub hyperexcitability.

It should be noted that, despite anatomical evidence for direct connections, our manipulations are not projection-specific, and 
therefore we cannot completely rule out the involvement of intervening structures in these effects. However, we believe that the regions manipulated here form vital nodes in the circuit for several reasons. First, while the RE receives a diverse array of afferent inputs (McKenna and Vertes, 2004), its major projection targets are restricted primarily to the hippocampus and the mPFC (Vertes, 2002; Vertes et al., 2006). Given that our NMDA infusions targeted the portion of the RE that contains primarily neurons projecting to the ventral hippocampus (i.e., the rostral portion; Vertes et al., 2006), RE-mPFC projections are not likely involved in the responses observed. In addition, our data show a complete reversal of the effect of RE stimulation on VTA DA neuron population activity with vSub inhibition, supporting a direct RE-vSub action. Finally, although projections from the MPFC to the entorhinal cortex (Vertes, 2004) and from the mPFC to the VTA (Vertes, 2004) have been described anatomically, these circuits are unlikely to be involved in these findings given that RE inhibition completely reversed the effect of ilPFC inhibition on VTA DA neuron population activity. It should also be noted that recordings were performed in anesthetized animals. Nonetheless, whereas anesthesia is likely to impact baseline activity, it should not qualitatively impact the effects of pathway activation. The fact that our behavioral studies in awake animals were consistent with our electrophysiological findings supports this contention.

Together, our findings support a model whereby inactivation of the ilPFC leads to an increase in RE activity, driving the vSub and enhancing VTA DA neuron population activity (Fig. 5). We propose that the RE is a novel, key modulator of subcortical/limbic circuits involved in the control of VTA DA neuron firing, and as such could play a role in psychiatric illnesses involving dysfunction in these circuits. In particular, abnormally high DA tone underlies the pathophysiology of psychosis across psychiatric illnesses (Heinz and Schlagenhauf, 2010; Howes et al., 2012; Winton-Brown et al., 2014), most notably in schizophrenia (Howes et al., 2012). In addition, increased activity in the subiculum (Tregellas et al., 2007, 2014; Allen et al., 2012) and thalamus (Silbersweig et al., 1995; Tregellas et al., 2007) have been described in patients with schizophrenia. Our group has modeled the hippocampal hyperexcitability observed in schizophrenia using the methylazoxymethanol acetate (MAM) developmental disruption model, which exhibits enhanced VTA DA neuron population activity and aberrantly high vSub activity (Moore et al., 2006; Lodge and Grace, 2007; Modinos et al., 2015). Given that stimulation of RE was sufficient to replicate the hyperdopaminergic state observed in MAM animals, thalamic projections to the hippocampus could represent a key connection that perpetuates the subcortical hyperexcitability and hyperdopaminergic state seen in patients with schizophrenia. Indeed, this idea has been proposed, but never tested experimentally (Lisman et al., 2010). In addition, these findings are particularly interesting in light of recent studies demonstrating reduced functional connectivity between the $\mathrm{mPFC}$ and thalamus in patients with schizophrenia (Anticevic et al., 2014), a measure that can differentiate psychotic and nonpsychotic patients (Anticevic et al., 2015). This suggests that targeting thalamic regions that are interconnected in humans with both the mPFC and the hippocampus could represent an effective approach for developing novel treatments for psychotic disorders, including schizophrenia.

\section{References}

Allen P, Luigjes J, Howes OD, Egerton A, Hirao K, Valli I, Kambeitz J, FusarPoli P, Broome M, McGuire P (2012) Transition to psychosis associated with prefrontal and subcortical dysfunction in ultra high-risk individuals. Schizophr Bull 38:1268-1276. CrossRef Medline

Anticevic A, Cole MW, Repovs G, Murray JD, Brumbaugh MS, Winkler AM, Savic A, Krystal JH, Pearlson GD, Glahn DC (2014) Characterizing thalamo-cortical disturbances in schizophrenia and bipolar illness. Cereb Cortex 24:3116-3130. CrossRef Medline

Anticevic A, Savic A, Repovs G, Yang G, McKay DR, Sprooten E, Knowles EE, Krystal JH, Pearlson GD, Glahn DC (2015) Ventral anterior cingulate connectivity distinguished nonpsychotic bipolar illness from psychotic bipolar disorder and schizophrenia. Schizophr Bull 41:133-143. CrossRef Medline

Beier KT, Steinberg EE, DeLoach KE, Xie S, Miyamichi K, Schwarz L, Gao XJ, Kremer EJ, Malenka RC, Luo L (2015) Circuit architecture of VTA dopamine neurons revealed by systematic input-output mapping. Cell 162: 622-634. CrossRef Medline

Belujon P, Grace AA (2014) Restoring mood balance in depression: ketamine reverses deficit in dopamine-dependent synaptic plasticity. Biol Psychiatry 76:927-936. CrossRef Medline

Belujon P, Jakobowski NL, Dollish HK, Grace AA (2016) Withdrawal from acute amphetamine induces an amygdala-driven attenuation of dopamine neuron activity: reversal by ketamine. Neuropsychopharmacology 41:619-627. CrossRef Medline

Bertram EH, Zhang DX (1999) Thalamic excitation of hippocampal CA1 neurons: a comparison with the effects of CA3 stimulation. Neuroscience 92:15-26. CrossRef Medline

Bokor H, Csáki A, Kocsis K, Kiss J (2002) Cellular architecture of the nucleus reuniens thalami and its putative aspartatergic/glutamatergic projection to the hippocampus and medial septum in the rat. Eur J Neurosci 16:1227-1239. CrossRef Medline

Butts KA, Weinberg J, Young AH, Phillips AG (2011) Glucocorticoid receptors in the prefrontal cortex regulate stress-evoked dopamine efflux and aspects of executive function. Proc Natl Acad Sci U S A 108:18459-18464. CrossRef Medline

Cassel JC, Pereira de Vasconcelos A, Loureiro M, Cholvin T, Dalrymple-Alford JC, Vertes RP (2013) The reuniens and rhomboid nuclei: neuroanatomy, electrophysiological characteristics and behavioral implications. Prog Neurobiol 111: 34-52. CrossRef Medline

Chang CH, Grace AA (2013) Amygdala $\beta$-noradrenergic receptors modulate delayed downregulation of dopamine activity following restraint. J Neurosci 33:1441-1450. CrossRef Medline

Chang CH, Grace AA (2014) Amygdala-ventral pallidum pathway decreases dopamine activity after chronic mild stress in rats. Biol Psychiatry 76: 223-230. CrossRef Medline

Cholvin T, Loureiro M, Cassel R, Cosquer B, Geiger K, De Sa Nogueira D, Raingard H, Robelin L, Kelche C, Pereira de Vasconcelos A, Cassel JC (2013) The ventral midline thalamus contributes to strategy shifting in a memory task requiring both prefrontal cortical and hippocampal functions. J Neurosci 33:8772-8783. CrossRef Medline

Cornwall J, Cooper JD, Phillipson OT (1990) Projections to the rostral reticular thalamic nucleus in the rat. Exp Brain Res 80:157-171. Medline

Dolleman-Van der Weel MJ, Lopes da Silva FH, Witter MP (1997) Nucleus reuniens thalami modulates activity in hippocampal field CAl through excitatory and inhibitory mechanisms. J Neurosci 17:5640-5650. Medline

Duan AR, Varela C, Zhang Y, Shen Y, Xiong L, Wilson MA, Lisman J (2015) Delta frequency optogenetic stimulation of the thalamic nucleus reuniens is sufficient to produce working memory deficits: relevance to schizophrenia. Biol Psychiatry 77:1098-1107. CrossRef Medline

Ferenczi EA, Zalocusky KA, Liston C, Grosenick L, Warden MR, Amatya D, Katovich K, Mehta H, Patenaude B, Ramakrishnan C, Kalanithi P, Etkin A, Knutson B, Glover GH, Deisseroth K (2016) Prefrontal cortical regulation of brainwide circuit dynamics and reward-related behavior. Science 351:aac9698. CrossRef Medline

Floresco SB, Todd CL, Grace AA (2001) Glutamatergic afferents from the hippocampus to the nucleus accumbens regulate activity of ventral tegmental area dopamine neurons. J Neurosci 21:4915-4922. Medline

Floresco SB, West AR, Ash B, Moore H, Grace AA (2003) Afferent modulation of dopamine neuron firing differentially regulates tonic and phasic dopamine transmission. Nat Neurosci 6:968-973. CrossRef Medline

Gill KM, Lodge DJ, Cook JM, Aras S, Grace AA (2011) A novel $\alpha 5$ GA $\mathrm{BA}(\mathrm{A}) \mathrm{R}$-positive allosteric modulator reverses hyperactivation of the dopamine system in the MAM model of schizophrenia. Neuropsychopharmacology 36:1903-1911. CrossRef Medline

Gill KM, Cook JM, Poe MM, Grace AA (2014) Prior antipsychotic drug treatment prevents response to novel antipsychotic agent in the methylazoxymethanol acetate model of schizophrenia. Schizophr Bull 40: 341-350. CrossRef Medline 
Grace AA, Bunney BS (1983) Intracellular and extracellular electrophysiology of nigral dopaminergic neurons-1. Identification and characterization. Neuroscience 10:301-315. CrossRef Medline

Grace AA, Bunney BS (1984) The control of firing pattern in nigral dopamine neurons: burst firing. J Neurosci 4:2877-2890. Medline

Hammad H, Wagner JJ (2006) Dopamine-mediated disinhibition in the CA1 region of rat hippocampus via D3 receptor activation. J Pharmacol Exp Ther 316:113-120. Medline

Heinz A, Schlagenhauf F (2010) Dopaminergic dysfunction in schizophrenia: salience attribution revisited. Schizophr Bull 36:472-485. CrossRef Medline

Hembrook JR, Mair RG (2011) Lesions of reuniens and rhomboid thalamic nuclei impair radial maze win-shift performance. Hippocampus 21: 815-826. CrossRef Medline

Hembrook JR, Onos KD, Mair RG (2012) Inactivation of ventral midline thalamus produces selective spatial delayed conditional discrimination impairment in the rat. Hippocampus 22:853-860. CrossRef Medline

Herkenham M (1978) The connections of the nucleus reuniens thalami: evidence for a direct thalamo-hippocampal pathway in the rat. J Comp Neurol 177:589-610. CrossRef Medline

Hoover WB, Vertes RP (2007) Anatomical analysis of afferent projections to the medial prefrontal cortex in the rat. Brain Struct Funct 212:149-179. CrossRef Medline

Hoover WB, Vertes RP (2012) Collateral projections from nucleus reuniens of thalamus to hippocampus and medial prefrontal cortex in the rat: a single and double retrograde fluorescent labeling study. Brain Struct Funct 217:191-209. CrossRef Medline

Howes OD, Kambeitz J, Kim E, Stahl D, Slifstein M, Abi-Dargham A, Kapur S (2012) The nature of dopamine dysfunction in schizophrenia and what this means for treatment: meta-analysis of imaging studies. Arch Gen Psychiatry 69:776-786. Medline

Ito HT, Zhang SJ, Witter MP, Moser EI, Moser MB (2015) A prefrontalthalamo-hippocampal circuit for goal-directed spatial navigation. Nature 522:50-55. CrossRef Medline

Laroche S, Davis S, Jay TM (2000) Plasticity at hippocampal to prefrontal cortex synapses: dual roles in working memory and consolidation. Hippocampus 10:438-446. CrossRef Medline

Layfield DM, Patel M, Hallock H, Griffin AL (2015) Inactivation of the nucleus reuniens/rhomboid causes a delay-dependent impairment of spatial working memory. Neurobiol Learn Mem 125:163-167. CrossRef Medline

Lerner TN, Shilyansky C, Davidson TJ, Evans KE, Beier KT, Zalocusky KA, Crow AK, Malenka RC, Luo L, Tomer R, Deisseroth K (2015) Intactbrain analyses reveal distinct information carried by SNc dopamine subcircuits. Cell 162:635-647. CrossRef Medline

Lisman JE, Pi HJ, Zhang Y, Otmakhova NA (2010) A thalamohippocampal-ventral tegmental area loop may produce the positive feedback that underlies the psychotic break in schizophrenia. Biol Psychiatry 68:17-24. CrossRef Medline

Lodge DJ, Grace AA (2006) The hippocampus modulates dopamine neuron responsivity by regulating the intensity of phasic neuron activation. Neuropsychopharmacology 31:1356-1361. CrossRef Medline

Lodge DJ, Grace AA (2007) Aberrant hippocampal activity underlies the dopamine dysregulation in an animal model of schizophrenia. J Neurosci 27:11424-11430. CrossRef Medline

McKenna JT, Vertes RP (2004) Afferent projections to nucleus reuniens of the thalamus. J Comp Neurol 480:115-142. CrossRef Medline

Modinos G, Allen P, Grace AA, McGuire P (2015) Translating the MAM model of psychosis to humans. Trends Neurosci 38:129-138. CrossRef Medline

Moore H, Rose HJ, Grace AA (2001) Chronic cold stress reduces the spontaneous activity of ventral tegmental dopamine neurons. Neuropsychopharmacology 24:410-419. CrossRef Medline

Moore H, Jentsch JD, Ghajarnia M, Geyer MA, Grace AA (2006) A neurobehavioral systems analysis of adult rats exposed to methylazoxymethanol acetate on E17: implications for the neuropathology of schizophrenia. Biol Psychiatry 60:253-264. CrossRef Medline
Patton MH, Bizup BT, Grace AA (2013) The infralimbic cortex bidirectionally modulates mesolimbic dopamine neuron activity via distinct neural pathways. J Neurosci 33:16865-16873. CrossRef Medline

Paxinos G, Watson C (2013) The rat brain in stereotaxic coordinates, Ed 7. New York: Academic.

Paz JT, Bryant AS, Peng K, Fenno L, Yizhar O, Frankel WN, Deisseroth K, Huguenard JR (2011) A new mode of corticothalamic transmission revealed in the Gria4(-/-) model of absence epilepsy. Nat Neurosci 14: 1167-1173. CrossRef Medline

Prasad JA, Macgregor EM, Chudasama Y (2013) Lesions of the thalamic reuniens cause impulsive but not compulsive responses. Brain Struct Funct 218:85-96. CrossRef Medline

Prasad JA, Abela AR, Chudasama Y (2016) Midline thalamic reuniens lesions improve executive behaviors. Neuroscience pii:S0306-4522(16)00114-7. CrossRef Medline

Pratt JA, Morris BJ (2015) The thalamic reticular nucleus: a functional hub for thalamocortical network dysfunction in schizophrenia and a target for drug discovery. J Psychopharmacol 29:127-137. CrossRef Medline

Sesack SR, Grace AA (2010) Cortico-basal ganglia reward network: microcircuitry. Neuropsychopharmacology 35:27-47. CrossRef Medline

Silbersweig DA, Stern E, Frith C, Cahill C, Holmes A, Grootoonk S, Seaward J, McKenna P, Chua SE, Schnorr L (1995) A functional neuroanatomy of hallucinations in schizophrenia. Nature 378:176-179. CrossRef Medline

Tregellas JR, Davalos DB, Rojas DC, Waldo MC, Gibson L, Wylie K, Du YP, Freedman R (2007) Increased hemodynamic response in the hippocampus, thalamus and prefrontal cortex during abnormal sensory gating in schizophrenia. Schizophr Res 92:262-272. CrossRef Medline

Tregellas JR, Smucny J, Harris JG, Olincy A, Maharajh K, Kronberg E, Eichman LC, Lyons E, Freedman R (2014) Intrinsic hippocampal activity as a biomarker for cognition and symptoms in schizophrenia. Am J Psychiatry 171:549-556. CrossRef Medline

Ungless MA, Grace AA (2012) Are you or aren't you? Challenges associated with physiologically identifying dopamine neurons. Trends Neurosci 35: 422-430. CrossRef Medline

Valenti O, Lodge DJ, Grace AA (2011) Aversive stimuli alter ventral tegmental area dopamine neuron activity via a common action in the ventral hippocampus. J Neurosci 31:4280-4289. CrossRef Medline

Varela C, Kumar S, Yang JY, Wilson MA (2014) Anatomical substrates for direct interactions between hippocampus, medial prefrontal cortex, and the thalamic nucleus reuniens. Brain Struct Funct 219:911-929. CrossRef Medline

Vertes RP (2002) Analysis of projections from the medial prefrontal cortex to the thalamus in the rat, with emphasis on nucleus reuniens. J Comp Neurol 442:163-187. CrossRef Medline

Vertes RP (2004) Differential projections of the infralimbic and prelimbic cortex in the rat. Synapse 51:32-58. CrossRef Medline

Vertes RP, Hoover WB, Do Valle AC, Sherman A, Rodriguez JJ (2006) Efferent projections of reuniens and rhomboid nuclei of the thalamus in the rat. J Comp Neurol 499:768-796. CrossRef Medline

Watabe-Uchida M, Zhu L, Ogawa SK, Vamanrao A, Uchida N (2012) Whole-brain mapping of direct inputs to midbrain dopamine neurons. Neuron 74:858-873. CrossRef Medline

White IM, Whitaker C, White W (2006) Amphetamine-induced hyperlocomotion in rats: hippocampal modulation of the nucleus accumbens. Hippocampus 16:596-603. CrossRef Medline

Wimmer RD, Schmitt LI, Davidson TJ, Nakajima M, Deisseroth K, Halassa MM (2015) Thalamic control of sensory selection in divided attention. Nature 526:705-709. CrossRef Medline

Winton-Brown TT, Fusar-Poli P, Ungless MA, Howes OD (2014) Dopaminergic basis of salience dysregulation in psychosis. Trends Neurosci 37: 85-94. CrossRef Medline

Wouterlood FG, Saldana E, Witter MP (1990) Projection from the nucleus reuniens thalami to the hippocampal region: light and electron microscopic tracing study in the rat with the anterograde tracer Phaseolus vulgaris-leucoagglutinin. J Comp Neurol 296:179-203. CrossRef Medline 